\title{
Evaluation of the efficacy of Acalypha wilkesiana leaves in managing cardiovascular disease risk factors in rabbits exposed to salt-loaded diets
}

\author{
Kingsley Omage ${ }^{1 *}$ (D, Marshall A. Azeke ${ }^{2}$ and Sylvia O. Omage ${ }^{3}$
}

\begin{abstract}
Background: This study was conducted to evaluate the therapeutic benefits of oral administration of extracts of Acalypha wilkesiana leaves on some serum parameters that are indicators or risk factors of cardiovascular diseases, in salt loaded rabbits.

Method: Thirty experimental rabbits used for this study were randomized into five groups (A to E) of six rabbits. Rabbits in groups A to D were given salt loaded diets. Groups B and C animals were also treated with aqueous and ethanol extracts of Acalypha wilkesiana leaves respectively while rabbits in group E served as control.

Results: Salt loading resulted in a significantly $(P<0.05)$ higher serum albumin, cholesterol, LDL-cholesterol and lower serum globulin, HDL-cholesterol, triglycerides, as compared with the control. Treatment with Acalypha wilkesiana leaf extracts (aqueous or ethanol), at a dose of $300 \mathrm{mg} / \mathrm{kg}$ body weight, resulted in a significantly $(P<0.05)$ higher serum triglycerides, HDL-cholesterol, globulin, and lower serum total protein, albumin, LDL-cholesterol, cholesterol, as compared with the control, in the salt loaded rabbits.
\end{abstract}

Conclusion: Acalypha wilkesiana may be useful in the management of risk factors of cardiovascular diseases.

Keywords: Acalypha wilkesiana, Salt loaded diet, Ethanol extract, Aqueous extract, Cholesterol

\section{Background}

Sodium, an essential nutrient, is the principal cation of extracellular fluid and a major determinant of intravascular fluid volume. There are considerable human and animal experimental studies implicating excessive dietary salt intake in cardiovascular diseases especially hypertension $[1,2]$. Increase in blood pressure leads to damages to the kidney, heart, blood vessels, brain and the eyes. Major risk factors are; age, elevated LDL-cholesterol level, low HDLcholesterol, microalbuminuria. Analysis of blood samples also show abnormalities in plasma fasting blood glucose, total cholesterol and HDL-cholesterol, etc. These deleterious effects of excess salt can be managed with the use of medications or medicinal herbs.

\footnotetext{
* Correspondence: omagekingsley@yahoo.com

${ }^{1}$ Department of Biochemistry, College of Basic Medical Sciences, Igbinedion University, Okada, Edo State, Nigeria

Full list of author information is available at the end of the article
}

Medicinal herbs are plants which contain substances that can be used for therapeutic purposes, of which are precursors for the synthesis of drugs [3]. Acalypha wilkesiana, commonly called Irish petticoat, Jacob's coat and Copper leaf (local name), belongs to the family Euphorbiaceae, subfamily Acalyphoideae, tribe Acalypheae. The plant is native to the south pacific islands (Bismarck Islands, Fiji, Vanuatu). The plant has been reported to contain sesquiterpenes, monoterpenes, triterpenoids and polyphenols [4]. The leaves reportedly contain saponins, tannins, anthraquinones and glycosides [5]. Characterization of $A$. wilkesiana leaf extracts by gas chromatograhy-mass spectrometry (GC-MS) indicated that glycoside, terpenes, and alkaloid were present while the major components detected from the isolated yellow oil of $A$. wilkesiana were 15 -hydroxy pentadecanoic acid, 2-ethyl - 2-methyl tridecanol, pentadecanal, n-decanoic acid and cholesterol [6]. GC-MS chromatogram of the aqueous leaf extract of $A$. wilkesiana muell 
arg indicated the presence of nine compounds (mostly straight chain alkanes) which includes iminostilbene, 5acetyl-2-amino-4-methyl thiazole, pentadecane, octadecane, eicosane, heptadecane, nonadecane, tetratriacontane, 2-decyldodecylcyclohexane and 2-methyltricosa ne, as well as carboxylic acids [7]. These alkanes have been reported to possess a good antimicrobial effect especially on Enterococcus faecalis and Staphylococcus aureus [7].

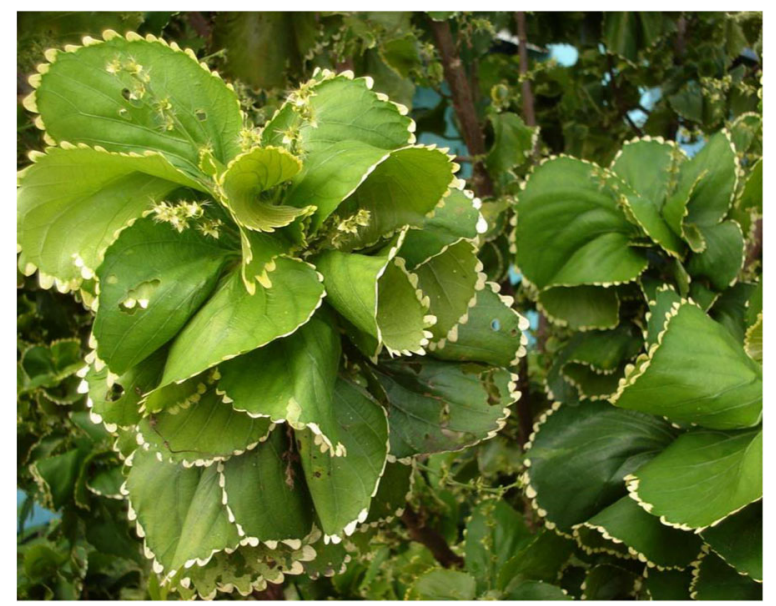

The plant has antimicrobial and antifungal properties and in traditional medicine, the leaves are eaten as vegetables in the management of hypertension, a risk factor for cardiovascular diseases, being a diuretic plant. However, the scientific basis for its use in the management of risk factors of cardiovascular diseases has not been rationalized. Thus, the aim of this study was to evaluate the effects of oral administration of extracts of Acalypha wilkesiana leaves on some serum parameters that are indicators or risk factors of cardiovascular diseases, with a view to ascertaining its therapeutic benefits, using salt loaded experimental rabbits.

\section{Methods}

\section{Plant materials}

Acalypha wilkesiana leaves were purchased from gardens within Benin City and authenticated at the Department of Plant Biology and Biotechnology, University of Benin, Benin City. The leaves were properly selected to remove unwanted materials and then air dried. The dried leaves were then pulverized into fine powder and weighed.

\section{Preparation of ethanol extract}

Two hundred grams of the pulverized leaves was soaked in $800 \mathrm{ml}$ of ethanol (95\%) for $72 \mathrm{~h}$ (3 days). The mixture was occasionally stirred using a magnetic stirrer to ensure proper mixture of the vessel content. The content was then filtered using a sintered funnel, (which is equivalent to four folds of bandage or sheet of cheese cloth). The extract (filtrate) was then concentrated using rotary evaporator and weighed [4].

\section{Preparation of aqueous extract}

Two hundred grams of the pulverized leaves was soaked in $800 \mathrm{ml}$ of distilled water for $72 \mathrm{~h}$ (3 days), and treated as described above for ethanol extract [4].

\section{Preparation of salt-loaded diet (feed)}

The salt-loaded diet ( $8 \% \mathrm{NaCl}$ and $92 \%$ feed) used for this study was prepared by mixing eight (8) grams of analytical $\mathrm{NaCl}$ (from $\mathrm{BDH}$ Chemicals, England) with ninety-two (92) grams of the feed. The mixture was fed to the experimental rabbits, ad libitum [8], as described in the experimental design below.

\section{Experimental animals}

Thirty adult male rabbits of the New Zealand strain, weighing between 1.0-1.6 kg, were used for this study. The experimental rabbits were obtained from local breeders within Benin City. The rabbits were kept in the animal house of the Department of Biochemistry, University of Benin and maintained on a 12-h light and dark cycle in clean disinfected cages. They were allowed free access to feed (standard pelletized growers feed from UAC- Vital Feed, Jos, Plateau State) and water throughout the duration of the experiment. Prior to the commencement of the study, the animals were allowed to adjust and adapt to the new environment for a period of 3 weeks [9]. The experimental procedures performed on the animals were approved by the Animal Ethics Committee of the Faculty of Life Sciences, University of Benin, Nigeria. The use of rabbits for the study was also according to the Ethical Guidelines Involving Whole Animal Testing of the Animal Ethics Committee, Faculty of Life Sciences, University of Benin. After 3 weeks of acclimatization, the experimental rabbits were then randomized into five groups (A to E) of six (6) rabbits each.

\section{Experimental design}

The rabbits in the groups, A, B, C, D and E were treated as follows;

Group A rabbits: were given continuous salt-loaded diet.

Group B rabbits: were given salt-loaded diet and treated with aqueous extract.

Group C rabbits: were given salt-loaded diet and treated with ethanol extract.

Group D rabbits: were given salt-loaded diet and not treated with the extract.

Group E rabbits: were neither given salt loaded diet nor treated with the extract (Control). 
Groups A, B, C and D rabbits were fed with the saltloaded diet for a period of seventy (70) days. After the 70th day, group A animals were maintained on the salt loaded diet till the 77th day while groups $B$ and $C$ animals were discontinued on the salt loaded diet (after the 70th day) and treated with aqueous and ethanol extracts of Acalypha wilkesiana leaves respectively, till the 77th day (i.e. for a period of 7 days). Also, after the 70th day, group $\mathrm{D}$ animals were discontinued on the salt-loaded diet and given normal diet till the 77th day, while group $\mathrm{E}$ animals were neither given salt-loaded diets nor treated with the extract throughout the duration of the experiment (i.e. it served as control) [8].

\section{Administration of Extracts}

Five grams of the concentrated extracts were suspended in distilled water for administration to the experimental animals. The extracts (aqueous or ethanol) were administered orally at a dose of $300 \mathrm{mg} / \mathrm{kg}$ body weight for a period of 7 days [8].

\section{Collection of blood}

After 70 days of salt loaded diets and prior to treatment (i.e. Day 71) with the extracts, blood samples were collected from the veins located on the dorsal side of the ear lobes of the experimental animals (rabbits), using sterilized hypodermic needles. Also, on the 78th day, after treatment with the extracts for a period of 7 days, blood samples were collected from the animals. Blood samples were collected into plane sterile universal tubes immersed in ice. The tubes were centrifuged at $3500 \mathrm{rpm}$ for $10 \mathrm{~min}$ and clear serum obtained which were used for further analysis [8].

\section{Assay methods}

Triacylglycerol (TG) and Total Cholesterol (Chol) were determined by the method of Neetu and Neelima, (2013) [10]. HDL - Cholesterol (HDL) was determined by the method of Leticia, (2014) [11]. LDL - Cholesterol (LDL) was by the equation of Friedwald [12]. (LDL-cholesterol $(\mathrm{mg} / \mathrm{dl})=$ Total Cholesterol $-\mathrm{TG} / 5-\mathrm{HDL}$ cholesterol). Glucose was determined by the methods of Basul et al. [13] and Renjie et al. [14]. Total Protein (TP) was determined by the method of Dipali et al. [15], (Biuret method). Albumin (ALB) was by dye binding method [16]. The amount of Globulin (GLB) was calculated as a difference between total serum proteins and serum albumin. All reagents were purchased from RANDOX DIAGNOSTIC, UK.

\section{Statistical analysis}

Data are represented as Mean \pm S.E.M $(n=6)$. Significance of difference was tested by Student t-Test, ANOVA and Turkey-Kramer test, using the GraphPad Instat Version 3 (GraphPad Software Inc. San Diego, California U.S.A.). Statistical Significance was set at $P<0.05$.

\section{Results}

The effects of oral administration of extracts (aqueous and ethanol) of Acalypha wilkesiana leaves on some serum parameters in salt loaded experimental rabbits, are as described below.

Table 1 shows the effect of salt loading for 70 days on the mean serum cholesterol, triglycerides, HDLcholesterol and LDL-cholesterol levels ( $\mathrm{mg} / \mathrm{dl}$ ) of normal rabbits. All the groups given salt load (groups A, B, C and $\mathrm{D})$ showed significantly $(P<0.05)$ higher levels of cholesterol, LDL-cholesterol and lower levels of triglycerides, HDL-cholesterol as compared with the control (group E), after 70 days of salt loading. Administration of the extracts (aqueous or ethanol) of Acalypha wilkesiana leaves, at a dose of $300 \mathrm{mg} / \mathrm{kg}$ body weight for a period of 1 week, resulted in significantly $(P>0.05)$ lower levels of cholesterol, LDL-cholesterol and higher triglycerides, HDL-cholesterol levels.

Table 1 Serum Cholesterol, Triglycerides, HDL-Cholesterol, LDL-Cholesterol (mg/dl) of salt-loaded rabbits; treated with aqueous (B) and ethanol (C) extracts of Acalypha wilkesiana leaves, continuous salt loading (A), salt loaded and non-treated (D), non-loaded and non-treated $(\mathrm{E})$

\begin{tabular}{|c|c|c|c|c|c|c|}
\hline \multirow[b]{2}{*}{ SERUM } & \multirow[b]{2}{*}{ DAY } & \multicolumn{5}{|l|}{ GROUP } \\
\hline & & A (Cont. Salt) & B (Salt + Aq. Ext) & $C$ (Salt +Et. Ext) & $D($ Salt + No Ext) & E (Control) \\
\hline \multirow[t]{2}{*}{$\mathrm{CHOL}(\mathrm{mg} / \mathrm{dl})$} & 71 & $94.69 \pm 8.06$ & $93.09 \pm 6.03^{*}$ & $96.93 \pm 8.57^{*}$ & $91.51 \pm 3.36$ & $59.04 \pm 6.83$ \\
\hline & 78 & $99.96 \pm 5.36$ & $70.18 \pm 3.92^{* *}$ & $64.32 \pm 7.00^{* *}$ & $86.92 \pm 6.05$ & $60.27 \pm 5.61$ \\
\hline \multirow[t]{2}{*}{ TG (mg/dl) } & 71 & $77.47 \pm 8.46$ & $75.28 \pm 7.94^{*}$ & $73.09 \pm 8.3^{*}$ & $73.76 \pm 9.34$ & $118.22 \pm 9.32$ \\
\hline & 78 & $70.53 \pm 4.63$ & $84.64 \pm 4.06^{* *}$ & $89.32 \pm 5.29^{* *}$ & $76.45 \pm 3.84$ & $118.40 \pm 8.97$ \\
\hline \multirow[t]{2}{*}{$\mathrm{HDL}(\mathrm{mg} / \mathrm{dl})$} & 71 & $48.41 \pm 2.87$ & $46.84 \pm 5.73^{*}$ & $46.98 \pm 6.78^{*}$ & $45.95 \pm 2.94$ & $86.32 \pm 5.92$ \\
\hline & 78 & $43.25 \pm 5.18$ & $67.73 \pm 7.85^{* *}$ & $65.77 \pm 3.73^{* *}$ & $49.66 \pm 8.90$ & $85.47 \pm 8.81$ \\
\hline \multirow[t]{2}{*}{ LDL (mg/dl) } & 71 & $14.65 \pm 8.47$ & $13.40 \pm 4.28^{*}$ & $12.96 \pm 5.82^{*}$ & $14.12 \pm 5.50$ & $-12.04 \pm 4.18$ \\
\hline & 78 & $17.24 \pm 6.97$ & $6.09 \pm 5.38^{* *}$ & $4.08 \pm 9.64^{* *}$ & $12.04 \pm 4.12$ & $-11.31 \pm 3.05$ \\
\hline
\end{tabular}

Data represent Means \pm S.E.M $(n=6)$. For each serum parameter, Means with different symbol ${ }^{*}$, ${ }^{* *}$ along columns, are significantly different $(p<0.05)$ 
Table 2 shows the effect of salt loading for 70 days on the mean plasma glucose, serum albumin, globulin and total protein levels $(\mathrm{mg} / \mathrm{dl})$ of normal rabbits. All the groups given salt load (groups A, B, C and D) showed significantly $(P<0.05)$ higher levels of albumin and significantly lower levels of globulin, as compared with the control (group E), after 70 days of salt loading. Administration of the extracts (aqueous or ethanol) of Acalypha wilkesiana leaves, at a dose of $300 \mathrm{mg} / \mathrm{kg}$ body weight for a period of 1 week, resulted in significantly $(P>0.05)$ lower levels of albumin, total protein and significantly higher levels of globulin.

\section{Discussion}

Hypertriglyceridemia is a recognized risk factor for coronary heart disease [17]. High triglyceride (TG) is a trait common in many conditions, including insulin resistance, hypertension, and centrally mediated obesity [18], and in lipase deficiency $[19,20]$. Increased risk is thought to be manifested largely through a reduction in HDL cholesterol [17]. However, since elevated triglycerides result in significantly altered composition of all plasma lipoproteins, the contribution of other pathways to this increased pathology is possible.

As with the effect of salt load on plasma glucose levels of the experimental animals, the serum triglyceride also decreased due to salt loading. This may signify increased energy metabolism in the animals. Increased sodium also stimulated increased lipolysis and glycogenesis. This may be responsible for the decreases in the levels of glucose and triglycerides. Treatment with the extracts resulted in further decreases in the plasma glucose levels and significantly higher serum triglycerides, as compared with the untreated group. This may suggest a sparing effect of the plant on the triglycerides breakdown with consequent increase in glucose utilization. Thus, salt loading tends to increase the breakdown of triglycerides or increase the rate of lipolysis.

The liver both produces and breaks down cholesterol, as needed. Broken down cholesterol is normally excreted into the bile, but with chronic hepatitis $\mathrm{C}$, there is sometimes a blockage of bile flow either inside the liver (due to cirrhosis) or outside the liver (most often due to gallstones), as a result of which blood cholesterol rises. The more the bile flow is obstructed, the more elevated the cholesterol will become. The increase in total cholesterol may be due to cirrhosis or gallstones, since it is significant. The significantly lower cholesterol levels after treatment with the extract may be possibly due to the steroids (phytosterols) constituent of the plant leaves [4], as reported in our previous study of the plant, which is higher in the ethanol extract. The plasma cholesterol-lowering properties of plant sterols have been known since the 1950s [21]. The composition of plant sterols and plant stanols lowers blood cholesterol levels by inhibiting the absorption of dietary and endogenously produced cholesterol from the small intestine and the plant sterols/stanols are only poorly absorbed themselves.

Cholesterol contained in HDL particles is considered beneficial for the cardiovascular health, in contrast to "bad" LDL cholesterol [22]. HDL serves to remove cholesterol from peripheral cells to the liver, where the cholesterol is converted to bile acids and excreted into the intestine [23]. This function may be affected by salt load as it resulted in lower serum HDL-cholesterol levels of the experimental animals. After 1 week of treatment with the extracts (aqueous or ethanol) of Acalypha wilkesiana leaves, the HDL-cholesterol levels were seen to be significantly higher in the treated groups, when compared with the untreated group (D). This indicates the possible protective or beneficial effect of the plant with respect to cardiovascular health. An inverse relationship between HDL-cholesterol levels in serum and the

Table 2 Plasma Glucose (mg/dl) and serum Albumin, Globulin, Total Protein ( $\mathrm{g} / \mathrm{dl})$ of salt-loaded rabbits; treated with aqueous (B) and ethanol (C) extracts of Acalypha wilkesiana leaves, continuous salt loading (A), salt loaded and non-treated (D), non-loaded and non-treated (E)

\begin{tabular}{|c|c|c|c|c|c|c|}
\hline & \multirow[b]{2}{*}{ DAY } & \multicolumn{5}{|l|}{ GROUPS } \\
\hline & & A (Cont. Salt) & $B($ Salt + Aq.Ext) & $C$ (Salt + Et.Ext) & $D($ Salt + NoExt $)$ & E (Control) \\
\hline \multirow[t]{2}{*}{ PLASMA GLUCOSE (mg/dl) } & 71 & $74.13 \pm 8.82$ & $73.33 \pm 8.11$ & $77.47 \pm 6.85$ & $76.53 \pm 6.33$ & $94.80 \pm 5.05$ \\
\hline & 78 & $72.75 \pm 2.79$ & $66.75 \pm 0.82$ & $67.26 \pm 0.83$ & $80.23 \pm 4.67$ & $95.30 \pm 4.52$ \\
\hline \multirow[t]{2}{*}{ SERUM ALBUMIN (g/dl) } & 71 & $6.33 \pm 0.74$ & $6.15 \pm 1.08^{*}$ & $5.87 \pm 0.43^{*}$ & $5.60 \pm 0.54$ & $2.92 \pm 0.18$ \\
\hline & 78 & $7.08 \pm 0.09$ & $3.58 \pm 0.42^{* *}$ & $2.70 \pm 0.32^{* *}$ & $4.57 \pm 0.39$ & $2.85 \pm 0.26$ \\
\hline \multirow[t]{2}{*}{ SERUM GLOBULIN (g/dl) } & 71 & $1.16 \pm 0.83$ & $1.08 \pm 0.29^{*}$ & $1.15 \pm 1.05^{*}$ & $1.07 \pm 0.15$ & $3.67 \pm 1.29$ \\
\hline & 78 & $1.02 \pm 0.35$ & $1.95 \pm 0.94^{*}$ & $2.03 \pm 0.22^{*}$ & $1.56 \pm 0.54$ & $3.71 \pm 0.68$ \\
\hline \multirow[t]{2}{*}{ SERUM TOTAL PROTEIN (g/dl) } & 71 & $6.48 \pm 0.17$ & $6.66 \pm 0.10^{*}$ & $6.89 \pm 1.57^{*}$ & $6.28 \pm 0.06$ & $7.39 \pm 1.01$ \\
\hline & 78 & $6.11 \pm 0.24$ & $4.02 \pm 0.35^{* *}$ & $4.79 \pm 0.17^{* *}$ & $6.62 \pm 0.38$ & $7.59 \pm 0.85$ \\
\hline
\end{tabular}

Data represent Means \pm S.E.M $(n=6)$. For each serum parameter, Means with different symbol ${ }^{*},{ }^{* *}$ along columns, for each parameter, are significantly different $(p<0.05)$ 
incidence or prevalence of coronary heart disease (CHD) has been demonstrated in a number of epidemiological studies. The importance of HDL-cholesterol as a risk factor for CHD is however recognized [24].

Studies have repeatedly demonstrated a strong association between both total and LDL-cholesterol concentration and coronary heart risk. There is a strong link between mean fat consumption, mean serum cholesterol concentration and the prevalence of coronary heart disease. The exception is where cardiovascular risk is only moderate-perhaps owing to high alcohol consumption [25]. In recent times, there has been a decline in the prevalence of atherosclerosis and atherosclerosis -related deaths possibly due to effective management of the risk factors that predispose to this disorder. The major identified risk factors are elevated LDL-cholesterol, reduced HDL-cholesterol [26] hypertension and noninsulin dependent diabetes mellitus [27]. Lowering of serum lipid concentrations, particularly LDL and VLDL fractions is therefore considered as one of the strategies that can delay the on-set of chronic disorders associated with hyperlipidemia in humans. The plant (A. wilkesiana) may be beneficial in this respect, since treatment with the extracts of the leaves resulted in decreases in the serum levels of LDL-cholesterol and corresponding increases in the serum levels of HDL-cholesterol.

According to the low-density-lipoprotein (LDL) receptor hypothesis, development of atherosclerosis is caused by a high concentration of LDL-cholesterol in the blood. Lowering LDL-cholesterol concentration therefore reverses, or at least retards the onset of atherosclerosis, thus preventing cardiovascular disease. Research findings have proved that lowering the concentrations of plasma lipids could diminish the complications of atherosclerosis and hypertension thereby prolonging life [28, 29].

The observations that salt increases glycaemic response attracted considerable attention in the light of the observed association between hypertension and diabetes [30, 31]. Reports by Yang et al. [32], Idowu et al. [33] and Ma et al. [34] had further highlighted some of the severe complications associated with both diseases. However, the plant may be a potential hypoglycemic or anti-diabetic agent, since it had a reducing effect on the plasma glucose levels.

Total protein, a measurement of all the proteins in the blood (many of which are produced by the liver), is a test of the functional status of the liver. Salt loading had no effect on serum total protein $(\mathrm{g} / \mathrm{dl})$ of the experimental animals. However, administration of the extracts resulted in significant decreases in the levels of total protein. This may be connected with the protein content of the leave which is lower in the aqueous extract and higher in the ethanol extract, comparatively [3], as our previous study showed. Proteins demonstrate numerous biological functions such as enzymes, regulator of metabolism, as antibodies and component of complement system. Plasma proteins maintain the osmotic pressure of plasma. They transport hormones, vitamins, metals and drugs often serving as reservoirs for their use. Most plasma proteins are synthesized in the liver, and are of relevance to the clinical laboratory. The most common changes in the protein concentration in disease result from the acute phase reaction proteins. Examples of such proteins are $\mathrm{X}_{1}$-antitrypsin, $\alpha$-acid glycoprotein, ceruloplasmin, Albumin, transferin hepaloglobin etc. [35]

Salt loading resulted in significantly higher serum albumin $(\mathrm{g} / \mathrm{dl})$ in all the groups given salt load. Albumin is essential for maintaining the oncotic pressure in the vascular system. The increase in albumin levels due to salt loading may be an attempt by the homeostatic mechanism of the animals to balance the effect of increased oncotic pressure due to salt load. Albumin helps in transporting small molecules through the blood, including bilirubin, calcium, progesterone, and medications [36], and plays an important role in keeping the fluid from the blood from leaking out into the tissues. However, administration of the extracts resulted in significant decreases in the serum albumin levels of the treated groups. Since sustained increase in sodium and chloride ions (occasioned by salt loading) expands asymptotically the extracellular fluid space by inducing thirst and water drinking and causing, through its osmotic action, an internal redistribution of fluid from the intra- to extracellular compartment, the liver possibly up-regulated the synthesis of albumin to balance the oncotic pressure to ensure normal physiology. This however, may be countered by the effect of the plant as occasioned by the decrease in albumin levels after treatment with the extracts (aqueous or ethanol). In those with ascites, a complication of liver cirrhosis that results in an abnormal accumulation of fluid in the abdomen, there may also be up-regulated albumin synthesis, but blood levels will be low due to the larger volume of distribution.

Salt loading resulted in significantly lower levels of serum globulin. The globulins perform a number of enzymatic functions in the plasma, but equally important, they are principally responsible for the body's both natural and acquired immunity against invading organisms [37]. High salinity tends to decrease or depress the normal synthesis of globulin in the experimental animals, which was relieved at cessation of salt load, as indicated in the untreated group. Administration of the extracts however, also resulted in an increase in the globulin levels, with the aqueous extract shown to be significantly higher. This may be connected with the actions of some of the phytochemical constituents of this plant like the flavonoids, saponins and anthraquinones [5], which are related to immune functions. 


\section{Conclusion}

Salt loading resulted in; increased LDL-cholesterol, total cholesterol, albumin and decreased triglycerides, HDLcholesterol, globulin, which are risk factors for cardiovascular diseases. But treatment with Acalypha wilkesiana leave extracts (aqueous or ethanol) had a reducing effect on the serum LDL-cholesterol, total cholesterol, albumin, total protein and an increasing effect on HDLcholesterol, globulin, which is beneficial in the management of cardiovascular diseases. Thus, Acalypha wilkesiana may be useful, as claimed in traditional medicine, in the management of cardiovascular diseases.

\section{Abbreviations}

ALB: Albumin; Aq.: Aqueous; BCG: Bromocresol green; CHD: Coronary Heart Disease; CHOL: Cholesterol; CVD: Cardiovascular Diseases; Et.: Ethanol; Ext.: Extract; GLOB: Globulin; HDL: High Density Lipoprotein; LDL: Low Density Lipoprotein; S.E.M: Standard Error of Mean; TG: Triglycerides; TP: Total Protein; VLDL: Very Low Density Lipoprotein

\section{Acknowledgments}

The Authors are grateful to the authorities of Department of Biochemistry, University of Benin (Edo State, Nigeria) for providing the necessary laboratory facilities.

\section{Authors' contributions}

OK: Concepts, Design, Experimental Studies, Data acquisition and Analysis, Manuscript preparation, Statistical Analysis. AAM: Concepts, Design, Experimental Studies, Data acquisition and Analysis. IOS: Design, Experimental Studies, Data acquisition and Analysis. All authors read and approved the final manuscript.

\section{Competing interests}

The authors wish to state that there are no competing interests associated with this publication and there has been no significant financial support for this work that could have influenced its outcome.

\section{Publisher's Note}

Springer Nature remains neutral with regard to jurisdictional claims in published maps and institutional affiliations.

\section{Author details}

'Department of Biochemistry, College of Basic Medical Sciences, Igbinedion University, Okada, Edo State, Nigeria. ${ }^{2}$ Department of Biochemistry, Faculty of Natural Sciences, Ambrose Alli University, Ekpoma, Edo State, Nigeria. ${ }^{3}$ Department of Biochemistry, Faculty of Life Sciences, University of Benin, Benin, Edo State, Nigeria.

Received: 25 August 2017 Accepted: 2 January 2018

/ Published online: 31 January 2018

\section{References}

1. Jody LG, Jennifer JD, Shannon LL, Paul WS, David GE, William BF. Dietary sodium loading impairs microvascular function independent of blood pressure in humans: role of oxidative stress. J Physiol. 2012;590:5519-28.

2. Joe B, Shapiro J. Molecular mechanisms of experimental salt-sensitive hypertension. JAHA. 2012;1:3.

3. Omage K, Azeke AM, Ihimire II, Idagan AM. Phytochemical, proximate and elemental analysis of Acalypha Wilkesiana leaves. Scientific Journal of Pure and Applied Sciences. 2013;2(9):323-31.

4. Omage K, Azeke AM. Medicinal potential of Acalypha wilkesiana leaves. Advances in Research (AIR). 2014b;2(11):655-65.

5. Enwa FO. A preliminary study on antibacterial efficacy of the Methanolic extract of Acalypha wilkesiana leaves against selected clinical isolates. Adv Life Sci Technol. 2014;18:72-6.
6. Iyekowa O, Oviawe AP, Ndiribe JO. Antimicrobial activities of Acalypha Wilkesiana (red Acalypha) extracts in some selected skin pathogens Zimbabwe. J Sci Technol. 2016;11:48-57.

7. Akinloye DI, Osatuyi OA, Musibau OG, Yusuf AA, Adewuyi S. In vitro antioxidant activities, elemental analysis and some bioactive constituents of Acalypha wilkesiana Muell Arg and Acalypha wilkesiana java white leaf extracts. J Chem Soc Nigeria. 2016;41(2):150-7.

8. Omage K, Azeke AM. Serum Aminotransferase activities and Bilirubin levels in salt loaded experimental rabbits treated with aqueous and ethanol extracts of Acalypha wilkesiana leave. Nigeria Journal of Experimental and Clinical Biosciences. 2014a;2(1):37-41.

9. Omage K, Azeke AM, Orhue NEJ. Implications of oral administration of extracts of Acalypha wilkesiana leave on serum electrolytes, urea and creatinine in normal experimental rabbits. Biokemistri. 2015;27(2):56-62.

10. Neetu M, Neelima S. Blood viscosity, lipid profile and lipid peroxidation in Type-1 diabetic patients with good and poor Glycemic control. N Am J Med Sci. 2013:5(9):562-6.

11. Leticia O, Alberto D, George G, Nina V, Jorge M, Hirian A. Diets Containing Sea cucumber (Isostichopus badionotus) meals are Hypocholesterolemic in young rats. PLoS One. 2014;

12. Seth SM, Micheal JB, Mohamed BE, Eliot AB, Peter PT, John WM. Friedewald-estimated versus directly measured low-density lipoprotein cholesterol and treatment implications. J Am Coll Cardiol. 2013;62(8): 732-9.

13. Basu S, Yoffe P, Hills N, Lustig RH. The relationship of sugar to populationlevel diabetes prevalence: an econometric analysis of repeated crosssectional data. PLoS One. 2013;8(2):e57873.

14. Renjie Q, Yongxu C, Xuxiong H, Xugan W, Xiaozhen Y, Rui T. Effect of hypoxia on immunological, physiological response, and Hepatopancreatic metabolism of juvenile Chinese mitten crab Eriocheir Sinensis. Aquac Int. 2011;19(2):283-99.

15. Dipali JS, Hitesh AV, Mahesh KV, Ashok BK, Ravishankar BA. Comparative study on chronic Administration of go Ghrita (cow ghee) and Avika Ghrita (ewe ghee) in albino rats. Ayu. 2012;33(3):435-40.

16. Bates RG, Paabo M. Measurement of ph. In: Lundblad RL, editor. Handbook of biochemistry and molecular biology. 4th ed. Boca Raton: F. MacDonald Press; 2010. p. 709-13

17. Paul SJ, Donald AS, Adi EM, Om G, Yehuda H, Helena WR, Mark DS, John AS. America Association of Clinical Endocrinologists' guidelines for Management of Dyslipidemia and Prevention of atherosclerosis. Endocr Pract. 2012;18(1):1-78.

18. Michael M, Neil JS, Christie B, Vera B, Michael HC, Henry NG. Triglycerides and cardiovascular disease: a scientific statement from the America heart association. Circulation. 2011;123:2292-333.

19. Elizabeth KY, Cynthia C, Daniel LS. HDL-ApoE content regulates the displacement of hepatic lipase from cell surface Proteoglycans. Am J Pathol. 2009:175(1):448-57.

20. Iseghohi SO, Orhue NEJ, Omage K. Pre-exposure to Dennettia tripetala Ethanolic fruit extract prevents biochemical alterations in rats subsequently exposed to a single dose of carbon tetrachloride. Int J Pharmacol Phytochem Ethnomed. 6:8-16.

21. Zoe H, Julian SB. Plant sterols lower cholesterol, but increase risk for coronary heart disease. Online J Biol Sci. 2014;14(3):167-9.

22. Emma L. Cholesterol. Lipidomics Gateway. 2009;22:55-81.

23. Erifeta OG, Omage K, Uhumwangho SE, Njoya KH, Amegor OF, Okonkwo CA. Comparative evaluation of antioxidant effects of watermelon and Orange, and their effects on some serum lipid profile of Wistar albino rats. Int J of Nutri and Metab. 2011;3(8):97-102.

24. Erifeta OG, Omage K, Waliu AO. Comparative study on effects of water melon and Orange on Glycemic index, histopathology and body weight changes in Wistar albino rats following consumption. Asian J of Appl Sci. 2013;1(4):108-12.

25. Douglas BK. Iron behaving badly: inappropriate iron Chelation as a major contributor to the Aetiology of vascular and other progressive inflammatory degenerative diseases. BMC Med Genet. 2009;2:2.

26. Ime FA, Item JA, Edisua HI, Mary Al, Essien UE. Effect of traditional diets on oxidative stress and lipid profile of Alloxan induced diabetic rats. Afr J Food Sci. 2011:5(3):143-7.

27. Rama N, Reddy A. Antidiabetic activity of 2-amino-(5-Fluoro-2-Oxoindolin-3ylidene) Benzoxazole-5-Carbohydrazide in rats. J Biomed Pharmaceut Res. 2014;3(6):78-81. 
28. Enechi OC, Manyawo NL, Ugwu PCO. Effects of ethanol seed extract of Buccholzia coriacea (wonderful kola) on the lipid profile of albino rats. Afr J Biotechnol. 2013;12(32):5075-9.

29. Kevin CM, Andrea LL, Mathew SR, Mary RD, Belinda HJ, Shneyvas ED, James RB. Lipid-altering effects of a dietary supplement tablet containing free plant sterols and Stanols in men and women with primary

Hypercholesterolaemia: a randomized placebo-controlled crossover trial. Int J Food Sci Nutr. 2012;63(4):476-82.

30. Ebadollah H, Samaz NP, Jahanbaksh S, Rasoul A, Kamran S. Association between diabetic retinopathy and left ventricular dysfunction in diabetic patients with unstable angina. J Cardiovasc Thoraxic Res. 2012:4(4):113-7.

31. Masaaki M, Machiko I, Kazuo I, Kimihiko A. Impaired fasting glucose as an independent risk factor for hypertension among healthy middle-aged Japanese subjects with optimal blood pressure: the Yuport medical checkup Centre retrospective cohort study. Diabetol Metab Syndr. 2013:5:81.

32. Yang $\mathrm{H}$, Wang $\mathrm{Q}$, Zhu D. Influence of Euonymus Alatus Sied extracts on MDCK proliferation and high concentration of glucose induced cell injury. Life Sci J. 2008:5(4):41-6.

33. Idowu AT, Peter GCO, Liasu AO, Reuben O. Influence of acute intake of cooking salt and laboratory salt on Glyceamic response to glucose loading in rats. Nat Sci. 2009;7(11):70-3.

34. Ma H, Yang $\mathrm{Y}$, Cheng $\mathrm{S}$. Transforming growth factor in diabetes and renal disease. Nat Sci. 2009;7(1):91-5.

35. Aghagboren CO, Uadia OP, Omage K. Comparative Hypoglyceamic properties of Scoparia Dulcis and Loranthus begwensis as well as their effects on some biochemical parameters in normal and Alloxan-induced diabetic rats. J Pharmaceut Biol. 2014;4(1):31-40.

36. Pratt DS. Liver chemistry and function tests. In: Feldman M, Friedman LS, Brandt $L$, editors. Sleisenger and Fordtran's gastrointestinal and liver disease. 9th ed. Philadelphia: Saunders Elsevier; 2010. chap 73.

37. Bruning A, Gingelmaier A, Friese K, Mylonas I. New prospects for nelfinavir in non-HIV related diseases. Curr Mol Pharmacol. 2010;3P:91-7.

\section{Submit your manuscript to a SpringerOpen ${ }^{\circ}$ journal and benefit from:}

- Convenient online submission

- Rigorous peer review

- Open access: articles freely available online

- High visibility within the field

Retaining the copyright to your article

Submit your next manuscript at $\boldsymbol{s p r i n g e r o p e n . c o m ~}$ 